Rev. Ter. Ocup. Univ. São Paulo, v. 21, n. 2, p. i, maio/ago. 2010.

\title{
Editorial
}

\section{Educação interprofissional para práticas colaborativas: o futuro da formação de recursos humanos em saúde}

\author{
The interprofessional education for collaborative practice: \\ the future training of health workforce
}

A educação interprofissional se refere às ocasiões nas quais estudantes de duas ou mais profissões aprendem juntos durante parte significativa ou mesmo durante todo o tempo de seu treinamento profissional com o objetivo de cultivar e desenvolver práticas colaborativas, para promover o cuidado em saúde centrado na pessoa (CAIPE, 2010). Envolve situações onde o aprendizado ocorre por meio de interações entre estudantes de diferentes profissões, assim como de estudantes com profissionais de outras profissões.

O reconhecimento da importância da educação interprofissional como uma inovação capaz de ajudar a lidar com as mudanças globais da força de trabalho em saúde, provocadas pelas inovações das políticas públicas de saúde, levou, a OMS a criar um Grupo de Trabalho, em 2007, para articular uma melhor compreensão sobre esse assunto no contexto global.

Esse trabalho visou produzir um guia sobre como os países membros poderiam usar a colaboração interprofissional para contribuir com a formação de profissionais e equipes de saúde mais flexíveis e capazes de responderem com mais eficiência e efetividade ás necessidades locais da população.

Esse grupo de trabalho apresentou, em março de 2010, o relatório "Framework for Action on Interprofissional Education and Collaborative Practice".

Nele podemos encontrar uma avaliação sobre a colaboração interprofissional no mundo; a identificação de modelos bem sucedidos para a formação de equipes colaborativas e sugestões de ações que podem ser aplicadas junto aos sistemas locais de saúde.

Fornece ainda estratégias e ideias que podem ajudar na implementação da educação interprofissional e práticas colaborativas na elaboração das políticas de saúde.

Trata-se de um importante documento cujo conteúdo mostra que a educação interprofissional e as práticas colaborativas jogam um papel importante em facilitar a resolução da atual crise da força de trabalho em saúde, marcada pela fragmentação do trabalho e pela incapacidade de responder ás complexas necessidades de saúde de uma população específica e enfatiza o papel da educação interprofissinal em preparar os profissionais para desenvolverem a "prontidão colaborativa". Além disso, é enfático ao demonstrar as evidências que indicam que uma efetiva educação interprofissional possibilita a efetiva prática colaborativa.

O documento estimula docentes, profissionais e estudantes para engajarem-se no ensino, prática e aprendizado colaborativos e oferece uma estratégia guiada para o avanço da educação interprofissional e, portanto, deve ser divulgado e discutido por todos.

No Brasil, apesar de pouco, ou nada, sistematizada e desenvolvida nos atuais currículos universitários, a educação interprofissional tem se constituído como importante eixo orientador dos programas do Ministério da Saúde que incorporaram o conjunto das profissões da saúde. Tal tendência deverá ser fortalecida nos próximos anos e se configurar como uma nova guinada no ensino em saúde, de forma que é importante que esse debate cresça e ganhe maior visibilidade no contexto acadêmico.

\section{REFERÊNCIAS}

CAIPE, Principles of Interprofessional Education, 2010, disponível em http://www.caipe.org.uk/about-us/principles-of-interprofessional-education/ WHO, Department of Human Resources for Health, Framework for Action on Interprofessional Education \& Collaborative Practice, Geneva Switzerland, 2010. Disponível em: < http://www.who.int/hrh/resources/framework_action/en/>.

Elisabete Ferreira Mângia

Prof $^{a}$ Dr $^{\mathrm{a}}$ do Departamento de Fisioterapia,

Fonoaudiologia e Terapia Ocupacional da USP

Editora da Revista de Terapia Ocupacional da USP 